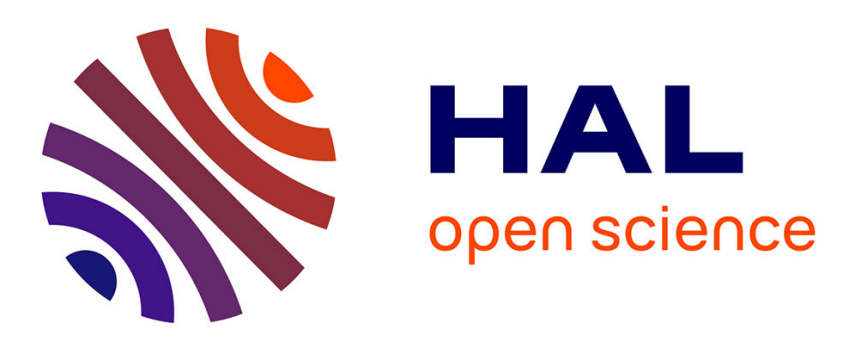

\title{
Climate Damage on Production or on Growth: What Impact on the Social Cost of Carbon?
}

Céline Guivarch, Antonin Pottier

\section{To cite this version:}

Céline Guivarch, Antonin Pottier. Climate Damage on Production or on Growth: What Impact on the Social Cost of Carbon?. Environmental Modeling \& Assessment, 2017, 10.1007/s10666-017-9572-4 . halshs-01612901

\author{
HAL Id: halshs-01612901 \\ https://shs.hal.science/halshs-01612901
}

Submitted on 17 Apr 2018

HAL is a multi-disciplinary open access archive for the deposit and dissemination of scientific research documents, whether they are published or not. The documents may come from teaching and research institutions in France or abroad, or from public or private research centers.
L'archive ouverte pluridisciplinaire $\mathbf{H A L}$, est destinée au dépôt et à la diffusion de documents scientifiques de niveau recherche, publiés ou non, émanant des établissements d'enseignement et de recherche français ou étrangers, des laboratoires publics ou privés. 


\title{
Climate damage on production or on growth: what impact on the social cost of carbon?
}

\author{
Céline GUIVARCH \\ CIRED \\ Ecole des Ponts ParisTech \\ 45 bis, avenue de la Belle \\ Gabrielle \\ 94736 Nogent-sur-Marne Cedex \\ guivarch@centre-cired.fr
}

\author{
Antonin PotTIER \\ MINES ParisTech \\ PSL Research University \\ CERNA - Centre for industrial \\ economics \\ i3, CNRS \\ 60, boulevard Saint-Michel \\ 75272 Paris Cedex 06 \\ antonin.pottier@mines- \\ paristech.fr
}

Note: this text is a post-print from the article: Guivarch, C. and A. Pottier. 2018. «Climate Damage on Production or on Growth: What Impact on the Social Cost of Carbon?». Environmental Modeling Assessment 23 (2) : 117-130.

\begin{abstract}
Recent articles have investigated with Integrated Assessment Models the possibility that climate damage bears on productivity (TFP) growth and not on production. Here, we compare the impact of these alternative representations of damage on the social cost of carbon (SCC). We ask whether damage on TFP growth leads to higher SCC than damage on production ceteris paribus. To make possible a controlled comparison, we introduce a measure of aggregate damage, or damage strength, based on welfare variations.

With a simple climate-economy model, we compare three damage structures: quadratic damage on production, linear damage on growth and quadratic damage on growth. We show that when damage strength is the same, the ranking of SCC between a model with damage on production and a model with damage on TFP growth is not unequivocal. It depends on welfare parameters such as the utility discount rate or the elasticity of marginal social utility of consumption.
\end{abstract}

JEL codes: Q51, Q54

keywords: climate change; damage; social cost of carbon; growth; TFP; IAM 


\title{
Climate damage on production or on growth: what impact on the social cost of carbon?
}

\author{
April 17, 2018
}

\begin{abstract}
Recent articles have investigated with Integrated Assessment Models the possibility that climate damage bear on productivity (TFP) growth and not on production. Here, we compare the impact of these alternative representations of damage on the social cost of carbon (SCC). We ask whether damage on TFP growth leads to higher SCC than damage on production ceteris paribus. To make possible a controlled comparison, we introduce a measure of aggregate damage, or damage strength, based on welfare variations.

With a simple climate-economy model, we compare three damage structures: quadratic damage on production, linear damage on growth and quadratic damage on growth. We show that when damage strength is the same, the ranking of SCC between a model with damage on production and a model with damage on TFP growth is not unequivocal. It depends on welfare parameters such as the utility discount rate or the elasticity of marginal social utility of consumption.
\end{abstract}

JEL codes: Q51, Q54

keywords: climate change; damage; social cost of carbon; growth; TFP; IAM

\section{Introduction}

The social cost of carbon ${ }^{1}$ (SCC) - the present social value of damage from an additional ton of $\mathrm{CO}_{2}$ released in the atmosphere - is an important concept in environmental policy. It represents the price that should be put on greenhouse gases emissions to maximize welfare in a first-best world. Indeed, along an optimal abatement path, abatement is such that marginal abatement cost equals the SCC. The SCC informs thus both on the level of expected climate change damage costs and on the level of effort in mitigation policies.

The SCC recently received close scrutiny for its direct role in policy evaluation (Interagency Working Group on Social Cost of Carbon (2010), Kopp et al. (2012), Greenstone et al. (2013), Pizer et al. (2014), Committee on Assessing Approaches to Updating the Social Cost of Carbon et al. (2017)). By monetizing the marginal damage associated with an incremental increase in emissions (equivalently the benefits associated with an incremental reduction), the SCC makes it possible to account for the social costs or benefits of regulatory actions that affect $\mathrm{CO}_{2}$ emissions. It can thus allow to compare policies and identify those that have positive net benefits. The values of the SCC currently in use for the evaluation of US federal rulemaking are for the year 2015: 11, 36, 56 and 105 in 2007 dollars per metric ton of $\mathrm{CO}_{2}$ (Interagency Working Group on Social Cost of Carbon,

\footnotetext{
${ }^{1}$ More accurately the social cost of $\mathrm{CO}_{2}$ as it relates to the impact of a ton of $\mathrm{CO}_{2}$ and not a ton of carbon. This is simply a question of changing units (from $\$ / \mathrm{tCO}_{2}$ to $\$ / \mathrm{tC}$ ) and not a different concept. We follow here the majority of the litterature by using the terminology Social Cost of Carbon.
} 
2015), the first three are tied to discount rates of 5,3 , and 2.5 percents, respectively, where the fourth is intended to represent the upper tail of the SCC distribution.

The tools used to quantify the social cost of carbon are called Integrated assessment models (IAMs). IAMs ${ }^{2}$ balance costs and benefits of climate change mitigation, in an economic model where both the emissions abatement costs and the climate change damage costs are introduced. Following the seminal work of Nordhaus $(1992,1994)$, damage costs from climate change have been represented in these models with a damage function that reduces the current economic production. In most models, damage thus bears on production. It is the case in particular in the three models used in the Interagency Working Group on Social Cost of Carbon (2015): DICE (Nordhaus, 2010), FUND (Anthoff and Tol, 2013) and PAGE (Hope, 2013).

The assumptions underlying this specification are questionable. There is a growing amount of evidence that damage may also bear on productivity growth rates rather than on production levels. Indeed some effects of climate change will be permanent, e.g. deaths from extreme events or destruction of ecosystems and land from sea level rise. Econometric studies also give empirical support for damage on GDP growth, e.g. Dell et al. (2009), Dell et al. (2012), Deryugina and Hsiang (2014), Colacito et al. (2014), Hsiang and Jina (2014). For example, Dell et al. (2012) used panel data to assess the impact of climate change on growth. They regressed growth rate on lagged temperatures. They found that temperature effect is significant for poor countries, and is persistent over a decade, suggesting an impact on growth rate rather than on production level. Or, Deryugina and Hsiang (2014) estimate the effect of daily temperature on annual income in United States counties and find that productivity of individual days declines by roughly $1.7 \%$ for each $1{ }^{\circ} \mathrm{C}$ increase in daily average temperature above $15^{\circ} \mathrm{C}$. These empirical research suggests that Total Factor Productivity (TFP) growth can be impacted by climate change and not only production levels. A theoretical argument raised by Moyer et al. (2014) goes in the same direction: in an endogenous growth model, damage on production level translates into damage on TFP. This gives sufficient reasons to investigate the impacts on SCC of damage on TFP growth.

Pindyck $(2011,2012)$ studied the effect of damage on growth for a measure of willingness to pay (WTP) to limit climate change to a given temperature increase, and found that WTP is lower than in the case of damage on production. But he did not investigate the effect on the SCC. It is only very recently that, following the recommendation of Revesz et al. (2014) to include damage on growth in IAMs, a few studies have investigated the possibility that climate damage bears on TFP growth, and not (or in addition to) on production (Dietz and Stern, 2015; Moyer et al., 2014; Moore and Diaz, 2015).

Moore and Diaz (2015) consider a two-region economy with damage on TFP growth and production calibrated on empirical data. They found that adding damage on TFP growth multiplies the SCC by a factor 6.7 in their central assumptions, compared to the case with damage on production only. Dietz and Stern (2015) or Moyer et al. (2014) "allocate" a share of damage costs on TFP growth ${ }^{3}$. With a share set at $5 \%$, which is qualified as "conservative" by the authors, the SCC is multiplied by a factor 2.7 (Dietz and Stern, 2015), compared to the case with no damage on TFP growth. These studies

\footnotetext{
${ }^{2}$ There are two different types of IAMs. First, the Cost-Benefit type concerned in this article. Second, a different type of IAMs, sometimes called process-based IAMs, that explicitly represent the drivers and processes of change in global energy and land use systems linked to the broader economy. The IAMs of this second type do not represent damage from climate change, and are used to analyze transformation pathways to achieve a pre-determined level of mitigation effort such as $2{ }^{\circ} \mathrm{C}$ climate stabilization, in a cost-effectiveness framework. Examples of process-based IAMs include the models used to quantify the Shared Socioeconomic Pathways (Riahi et al., 2017).

${ }^{3}$ Appendix 1 discusses why this allocation does not control for the magnitude of damage.
} 
concluded that damage on TFP growth leads to higher SCC than damage on production.

In this article, we ask a different question: which damage structure (on TFP growth or on production) leads to a higher SCC? Our approach is similar to Pottier et al. (2015), who investigate how the form of the damage function (quadratic vs. sigmoid) impacts the optimal SCC and abatement trajectories. To compare alternative structures of climate damage, we need to disentangle the effect of the structure (i.e. the functional form of the damage function and whether it bears on production or on growth) and the effect of the magnitude of damage.

Indeed, increasing the magnitude of damage increases the SCC, even without changing the damage structure. For example, in a model with damage on production: if we increase some parameter in the damage function, the SCC will increase too, and would eventually become larger than any SCC computed with a model with damage on growth with given parameters. So the SCC depends not only on the damage structure, but also on the magnitude of damage. The two are conceptually distinct and should not be confused. To put it differently, increasing some parameter of the damage function generally increases both the marginal damage, which the SCC is a measure of, and aggregate damage. To investigate the effect of a damage structure, we therefore have to track both the marginal damage (the SCC) and aggregate damage, and not the SCC only.

To sum up, in order to compare the impact on SCC of different damage structures, we need to define a measure of aggregate damage. With this to-be-defined measure, it becomes meaningful to say that, at an equal (aggregate) damage, the SCC is higher or lower when damage bears on growth rather than on production. The need of such a measure for controlled comparison is common in economics. For example, a comparison between constant discounting and hyperbolic discounting can be made by keeping the same degree of "impatience", that is an equal discount of a constant stream of revenues (Strulik, 2015).

The rest of the paper is organized as follows. Section 2 presents the simple climateeconomy model used and the three damage structures tested: conventional quadratic damage on production, linear damage on economic growth and quadratic damage on economic growth. Section 3 introduces our measure of the magnitude of damage, the damage strength, adapted from the Stern (2006) review. Section 4 compares how SCC varies across damage structures for an equal strength. We show that there is no unambiguous ranking of the structure, but that it depends mainly on the parameters of the social welfare function (the utility discount rate and the intertemporal elasticity of substitution). The comparison is then extended for the welfare gain of mitigation. Section 5 concludes with lessons learned and ways forward.

\section{The climate-economy model}

We use a very simple climate-economy model, based on the DICE model of Nordhaus (Nordhaus, 2008). The economic part is a copy from DICE. The climate module has been simplified from the DICE version, but with grounds in climate science (see the discussion below). To give an overview of this kind of model, it is a Solowian capital accumulation model with a climate feedback. There are two control variables: the saving rate, that controls the accumulation of capital, and the abatement rate, that controls the emissions and thus, through their accumulation, the temperature increase. Temperature increase feedbacks on production (or on TFP growth) through damage. 


\subsection{Economic module}

At time $t$, production $Q_{t}$ is made from capital $K_{t}$ and labor $L_{t}$ through a Cobb-Douglas function:

$$
Q_{t}=\Omega\left(T_{t}\right) A_{t} K_{t}^{\alpha} L_{t}^{1-\alpha}
$$

The total factor productivity (TFP) is $A_{t}$, and $\Omega\left(T_{t}\right)$ is the damage factor that reduces current production due to temperature increase $T_{t} ; \Omega$ is given by the following standard function:

$$
\Omega\left(T_{t}\right)=\frac{1}{1+\pi_{2} T_{t}^{2}}
$$

On top of this conventional damage factor, in our model, climate change acts as a drag on TFP growth. The exogenous trend $g_{t}$ is reduced endogenously by current temperature increase $T_{t}$ :

$$
\frac{A_{t+1}}{A_{t}}=1+g_{A t}\left(T_{t}\right)=1+g_{t}-\kappa_{1} T_{t}-\kappa_{2} T_{t}^{2}
$$

When at least one of the $\kappa$ is positive, this introduces a new type of damage: TFP growth rate is reduced and can even become negative when temperature increase is sufficiently high. The two control variables are the gross saving rate $s_{t}$ and the abatement (emission control) rate $\mu_{t}$. The capital stock is depreciated at rate $\delta$ and increases with investment:

$$
K_{t+1}-K_{t}=-\delta K_{t}+Q_{t} \cdot s_{t}
$$

Emissions abatement costs a fraction $\Lambda_{t}$ of the current production:

$$
\Lambda_{t}=\theta_{1}(t) \mu_{t}^{\theta_{2}}
$$

where $\theta_{1}(t)$ measures total costs and decreases exogenously, due to technical progress, and $\theta_{2}$ is the fixed exponent of the abatement rate $\mu_{t}$ in the abatement cost function, representing that, at a given time, reducing a higher share of emissions becomes more and more expensive $\left(\theta_{2}>1\right)$.

Total consumption is $C_{t}$ and equilibrium between resources and uses imposes that:

$$
Q_{t}=Q_{t} \Lambda_{t}+Q_{t} s_{t}+C_{t}
$$

\subsection{Climate module}

Emissions of greenhouse gases (here we just consider carbon dioxyde) are a by-product of production, partially offset by abatement $\mu_{t}$.

$$
E_{t}=\sigma_{t}\left(1-\mu_{t}\right) Q_{t}
$$

When there is no abatement $\mu_{t}=0$, emissions are proportional to production, with a carbon content of production $\sigma_{t}$ that decreases exogenously.

In most IAMs, emissions build up in the atmosphere. The carbon of the atmosphere is mixed between several carbon pools, which results in increasing concentrations. The 
atmosphere temperature is set through interactions with ocean temperature and forcing from GHG. This machinery represents some of the feedbacks that rules climate change in the real world.

Here we keep only the essential link between emissions and temperature. We set temperature increase to be proportional to the cumulative emissions. Thus temperature is simply given by:

$$
T_{t}=\beta \cdot\left(C E_{0}+\sum_{0 \leq s<t} E_{s}\right)
$$

where $\beta$ is the proportionality factor and $C E_{0}$ is the cumulative amount of emissions between pre-industrial times and the starting time of the model, such that the term in the parenthesis is the cumulative emissions since pre-industrial times at time $t$.

Although this is a crude representation of the climate system, with several drawbacks ${ }^{4}$, it has support in the climate community as the simplest rule of thumb to compute the reaction of global mean temperature to $\mathrm{CO}_{2}$ emissions accumulation. The ratio of global warming to cumulative carbon dioxide emissions has been shown to be almost independent of time and of emissions pathway in simulations of the response to a range of emissions scenarios with carbon climate models, as well as in observations (Matthews et al., 2009; Gillett et al., 2013). The latest estimations yield an observationally constrained $5 \%-95 \%$ range for the ratio of global warming to cumulative carbon dioxide emissions of $0.7 \mathrm{~K} / \mathrm{TtC}$ to $2.0 \mathrm{~K} / \mathrm{TtC}$. Goodwin et al. (2015) also give a theoretical foundation to this near-linear dependence between warming and cumulative carbon emissions, with a theoretically derived equation of the dependence of global warming on cumulative carbon emissions over time. They show the proportionality results from compensating effects of oceanic uptake of heat and carbon. Their analysis identifies a surface warming response to cumulative carbon emissions of $1.5 \pm 0.7 \mathrm{~K} / \mathrm{TtC}$.

We adopt this simple formula to ease computations but it is in no way an essential part of our argument.

\subsection{Damage structures}

In our model, climate damage has two main channels:

- the damage factor (equation (2)), which reduces current production relative to the possible production with the same amount of capital, labor, and technology (TFP), but without climate change.

- the impact of temperature increase on TFP growth (equation (3)), which reduces the technology (TFP) available in further period, compared to a case without climate change.

These direct channels feedback on the economic dynamics. These higher order effects occur mainly through the accumulation of capital, most notably via reduced savings (Fankhauser and Tol, 2005). This has the important consequence that both damage on production and on TFP growth have long lasting effects and reduce the apparent growth rate of the economy. This is one of the reason why it is hard to distinguish between damage on production and damage on TFP growth in empirical studies, that observe only economic outcomes and not the channels per se.

\footnotetext{
${ }^{4}$ In particular, Krasting et al. (2014) have shown that this linear relationship is influenced by prior emissions pathways, and Leduc et al. (2015) have shown that it is no longer valid for high emissions pathways such as the RCP8.5.
} 
To elucidate which kind of damage leads to the highest SCC, we consider three damage structures:

- quadratic damage on production: $\pi_{2}>0$ but $\kappa_{1}=0$ and $\kappa_{2}=0$. Note that in this case there is no impact of climate change on TFP, so that the TFP evolves exogenously. This is the standard case commonly used in IAMs.

- linear damage on growth: $\pi_{2}=0, \kappa_{1}>0$ and $\kappa_{2}=0$. The damage factor $\Omega$ stays equal to 1 , so that there is no direct damage on production. The only channel for damage is the reduction in growth that occurs linearly in temperature. This is the case studied in Pindyck (2011).

- quadratic damage on growth: $\pi_{2}=0, \kappa_{1}=0$ and $\kappa_{2}>0$. There is again no direct damage on production. Temperature increase impacts the TFP growth rate quadratically.

These three specifications represent "pure" damage structures, in the sense that they do not mix impacts on production and on growth, and that the dependence in temperature is either linear or quadratic. Note that Dietz and Stern (2015) or Moyer et al. (2014) combine quadratic damage on production with quadratic damage on TFP growth, whereas Moore and Diaz (2015) include both linear damage on growth and linear damage on production. In reality, both types of damage, on production and on growth are possible, and probably coexist. However, the aim of our contribution is not to study the most realistically calibrated damage, but instead to isolate the effect of changing the damage structure, while controlling for the damage strength. Previous studies that introduced damage on growth in an IAM did not study how the choices of the functional form and of the parameters values impacted the damage strength, nor compared different damage structures for the same strength.

\section{Methodological discussion: measure of aggregate climate damage and scenarios}

To compare the impact of the damage structure, we need to measure the magnitude of climate damage in our model. This "damage strength" will be assessed against a benchmark where there is no climate change; more precisely, it will be related to variations of intertemporal welfare. Thus the plan of this section: first, we define the scenarios to be considered in our comparison; second, we explain how we measure differences of welfare; third, we introduce the damage strength and related measures (mitigation gain, welfare loss).

\subsection{Scenarios under scrutiny}

We define three scenarios: the idealine ${ }^{5}$ (noted $i$ ), the baseline $(b)$ and the optimal policy $(o)$. In each, we say precisely how the control variables $\mu_{t}$ and $s_{t}$ are (endogenously) computed.

The benchmark scenario, against which damage strength is to be measured, is a scenario in an ideal economy when there is no climate damage. As damage is the only feedback of climate change on this economy, this is equivalent to say that there is no climate change in the model. In this ideal world, there is obviously no need for mitigation $\left(\mu_{t}=0\right)$, and

\footnotetext{
${ }^{5}$ What we call "idealine" is usually called "baseline" in the IAM community, in particular in the context of process-based IAMs studies on mitigation pathways and mitigation costs in a cost-effectiveness framework.
} 
the economy follows the optimal growth path where savings are optimized to maximise the intertemporal discounted sum of welfare. Thus the model reduces to the standard Ramsey-Solow model of capital accumulation. We call this scenario of optimal saving in a no-climate change economy the idealine, a contraction of ideal and baseline. The name reminds us that it is a pure hypothetical situation, and not a possible situation of the real world.

The baseline is the situation where climate damage impact the economy but no mitigation is undertaken, for whatever reasons. Abatement $\mu_{t}$ is zero and gross saving rates are those of the idealine. Contrary to the idealine, the baseline is a real possibility: it will be our world if no mitigation is ever implemented. This scenario could also be called laissez-faire scenario.

Finally, the third scenario to be considered is the optimal mitigation policy scenario: this is the scenario where the saving and abatement policy is chosen optimally, taking into account abatment cost and climate damage costs, to maximise intertemporal welfare.

The intertemporal welfare is given by the discounted utility flows weighted by population (so called total utilitarianism):

$$
W(C)=\sum_{t \geq 0} \frac{L_{t}}{(1+\rho)^{t}} u\left(\frac{C_{t}}{L_{t}}\right)
$$

where $\rho$ is the utility discount rate, and $u$ the utility function. The consumption stream $C_{t}$ is endogenously computed from control variables thanks to equations (1) to (8).

This optimal scenario is the one traditionally studied in IAMs in cost-benefit analysis. The SCC is computed along the optimal scenario thanks to the formula:

$$
S C C=-\frac{\partial_{E} W}{u^{\prime}\left(\frac{C_{0}}{L_{0}}\right)}
$$

where $\partial_{E} W$ represents the (negative) effect on welfare of an additional emission at date 0.

\subsection{Measuring variations of welfare between scenarios}

We are looking for a measure of welfare variation between scenarios.

Two scenarios, 1 and 2, have two corresponding consumption streams $C_{t}^{1}$ and $C_{t}^{2}$, and two intertemporal welfares $W^{1}$ and $W^{2}$. We will call the welfare variation of 2 compared to 1 , denoted by $w_{2 \mid 1}$, the proportional variation of the consumption stream $C^{1}$ that provides the same welfare as in scenario 2 , i.e. the quantity $w_{2 \mid 1}$ such that:

$$
W\left(C^{1}\left(1+w_{2 \mid 1}\right)\right)=W\left(C^{2}\right) .
$$

This is the "consumption loss, now and forever" experienced in scenario 2 compared to reference scenario 1 (obviously $w_{2 \mid 1}<0$ if welfare in 2 is less than in 1 ).

This measure of welfare variation is known under different names. In climate change economics, it is the relative change in balanced growth equivalent, that Nicholas Stern (2006) introduced in his review, following his early studies on balanced growth equivalent as a measure of intertemporal welfare (Mirrlees and Stern, 1972). The welfare variation can be simply computed, when the utility function is iso-elastic with the formula (the elasticity of marginal social utility of (per-capita) consumption being noted $\theta$ ):

$$
w_{2 \mid 1}=\left(\frac{W^{2}}{W^{1}}\right)^{\frac{1}{1-\theta}}-1
$$


When $\theta=1$, the formula is a little more complex, see Anthoff and Tol (2009) who have derived formulæ for several cases and computed growth equivalent variations with the FUND model.

In macro-economics, what we name welfare variation is called the welfare gain of a change from 1 to 2 (Lucas, 2003). It was famously applied by Lucas (1987, chap. III) on the welfare gain of eliminating the business cycle. The work of Pindyck $(2011,2012)$ uses the term willingness to pay (WTP) to avoid 2 while in 1 . This is minus the welfare variation.

\subsection{The strength of climate damage}

Following Stern (2006), we define the damage strength as minus the welfare variation of the baseline compared to the idealine $d=-w_{b \mid i}$. It is a measure of aggregate damage whereas the SCC is a measure of marginal damage. The damage strength is the maximum proportion of idealine consumption (where there is no climate change) that we would be ready to sacrifice in order to avoid the baseline (where climate damage occurs but no mitigation is undertaken). Equivalently, we could also say that it is the proportion of idealine consumption lost due to the existence of unmitigated climate change. Because there is no benefit to climate change in our model, damage strength is necessarily positive.

Comparing welfare in the idealine and the baseline is a good option to assess the damage strength, as it represents the maximum intertemporal damage that can affect the consumption path. It would make no sense to compare the idealine and the optimal policy. Indeed, in the latter, climate damage has been (partially) offset by mitigation. With our definition of damage strength, the difference of welfare arises just from climate damage and not from a combination of damage and mitigation policy.

Other welfare variations between the scenarios also have an economic meaning. The welfare variation between the optimal policy and the baseline can be named the mitigation gain $g=w_{o \mid b}$. The mitigation gain is a measure of how much mitigation policy improves welfare. It is the relevant measure to assess how effective mitigation policy can offset climate damage. Baseline and optimal policy are two specifications of policy variables within the same model. Because the optimal policy is maximizing the welfare, it yields a higher welfare than the baseline policy, i.e. mitigation gains are positive.

The welfare variation of the optimal policy against the idealine is the residual welfare loss due to climate change as offset by mitigation policy $l=-w_{o \mid i}$. The welfare loss is measured relative to a constant idealine (this does not depend on the damage), so the welfare loss is an inverse measure of the absolute welfare in the optimal mitigation scenario.

Due to the properties of welfare variation, damage strength, mitigation gain and welfare loss are related by the following relation:

$$
1-l=(1+g)(1-d) .
$$

When there is almost no mitigation gain, climate damage on the baseline cannot be reduced and the welfare loss is equal to the damage strength. If, on the contrary, mitigation gain are important, climate damage can be totally offset, and welfare loss would be almost null. We will see how these quantities behave depending on the damage structure.

\subsection{Damage structures, parameters and scenarios studied}

We computed a number of runs of the model combining:

- the type of scenario: idealine, baseline or optimal pathway, 


\begin{tabular}{|l|l|c|c|c|c|c|}
\hline \multirow{2}{*}{ runs } & \multirow{2}{*}{ scenarios } & \multicolumn{3}{|c|}{ damage function } & \multicolumn{2}{c|}{$\begin{array}{c}\text { social choice } \\
\text { parameters }\end{array}$} \\
& & $\pi_{2}$ & $\kappa_{1}$ & $\kappa_{2}$ & $\rho(\%)$ & $\theta$ \\
\hline $\begin{array}{l}\text { idealines (common } \\
\text { to all structures) }\end{array}$ & idealine & 0 & 0 & 0 & $1 ; 1.5 ; 2$ & $1 ; 2 ; 3$ \\
\hline $\begin{array}{l}\text { quadratic damage } \\
\text { on production }\end{array}$ & baseline & $0-0.027$ & 0 & 0 & $1 ; 1.5 ; 2$ & $1 ; 2 ; 3$ \\
\cline { 2 - 7 } & optimal pathway & $0-0.027$ & 0 & 0 & $1 ; 1.5 ; 2$ & $1 ; 2 ; 3$ \\
\hline $\begin{array}{l}\text { linear damage on } \\
\text { growth }\end{array}$ & baseline & 0 & $0-0.006$ & 0 & $1 ; 1.5 ; 2$ & $1 ; 2 ; 3$ \\
\cline { 2 - 7 } & optimal pathway & 0 & $0-0.006$ & 0 & $1 ; 1.5 ; 2$ & $1 ; 2 ; 3$ \\
\hline $\begin{array}{l}\text { quadratic damage } \\
\text { on growth }\end{array}$ & baseline & 0 & 0 & $0-0.002$ & $1 ; 1.5 ; 2$ & $1 ; 2 ; 3$ \\
\cline { 2 - 7 } & optimal pathway & 0 & 0 & $0-0.002$ & $1 ; 1.5 ; 2$ & $1 ; 2 ; 3$ \\
\hline
\end{tabular}

Table 1: Model runs computed in the study.

- the damage structure (the point of impact (production or TFP growth) and their functional form),

- the values of the parameters in the structure $\left(\pi_{2}, \kappa_{1}\right.$ and $\left.\kappa_{2}\right)$,

- the values of the social choice parameters $(\rho$ and $\theta)$.

The values of all other parameters are set to the values from DICE2007 (Nordhaus, 2008), and given in Appendix 2.

Table 1 summarizes the runs of the model computed for this study.

For the social choice parameters, we test a set of values, in the range of values recently used in IAM studies.

The disagreement about the value of the elasticity of marginal utility $(\theta)$ comes from the fact this parameter plays different roles in the discounted expected utility model: it simultaneously reflects preferences for intertemporal substitution, aversion to risk, and aversion to (spatial) inequality (Godard, 2009). Using estimates of the demand systems, Stern (1977) estimated its value around 2, with a range of roughly 0-10. More recently, in his Climate Change review (Stern, 2006), he advocated for a normative value equal to 1. In response to the Stern Review, Arrow (2007) suggest values around 2-3; and Dasgupta (2007) advocates for a value between 2 and 4. We chose to test the values 1, 2 and 3.

Although there exist some ethical grounds to justify very low values for the utility discount rate (Stern (2014a); Stern (2014b)), we chose to test a conservative range of values, recently used in IAM studies: $1 \%, 1.5 \%$ and $2 \%$.

\section{Results}

This section presents the results of our investigation.

For the three damage structures, we varied the damage parameters (either $\pi_{2}, \kappa_{1}$ or $\kappa_{2}$, depending on the structure) and calculated the damage strength and the SCC in the optimal scenario. For each damage structure, we thus obtained a curve that relates the SCC to the damage strength. With these curves, we can now compare whether a damage structure leads to a higher SCC for the same damage strength: this amounts to compare the position of a curve relative to the others.

For each combination of the welfare parameters, we plotted the SCC as a function of damage strength for the three structures. The dashed line with square marks represents quadratic damage on production. The solid line with circle marks represents linear damage on growth, whereas the solid line with square marks represents quadratic damage on 
growth. We have gathered all the graphs on figure 1: nine graphs with three curves on each. In figure 1 , columns share the same pure time-preference rate $\rho$, whereas rows share the same elasticity of marginal utility $\theta$. Both parameters increase from bottom left to top right.
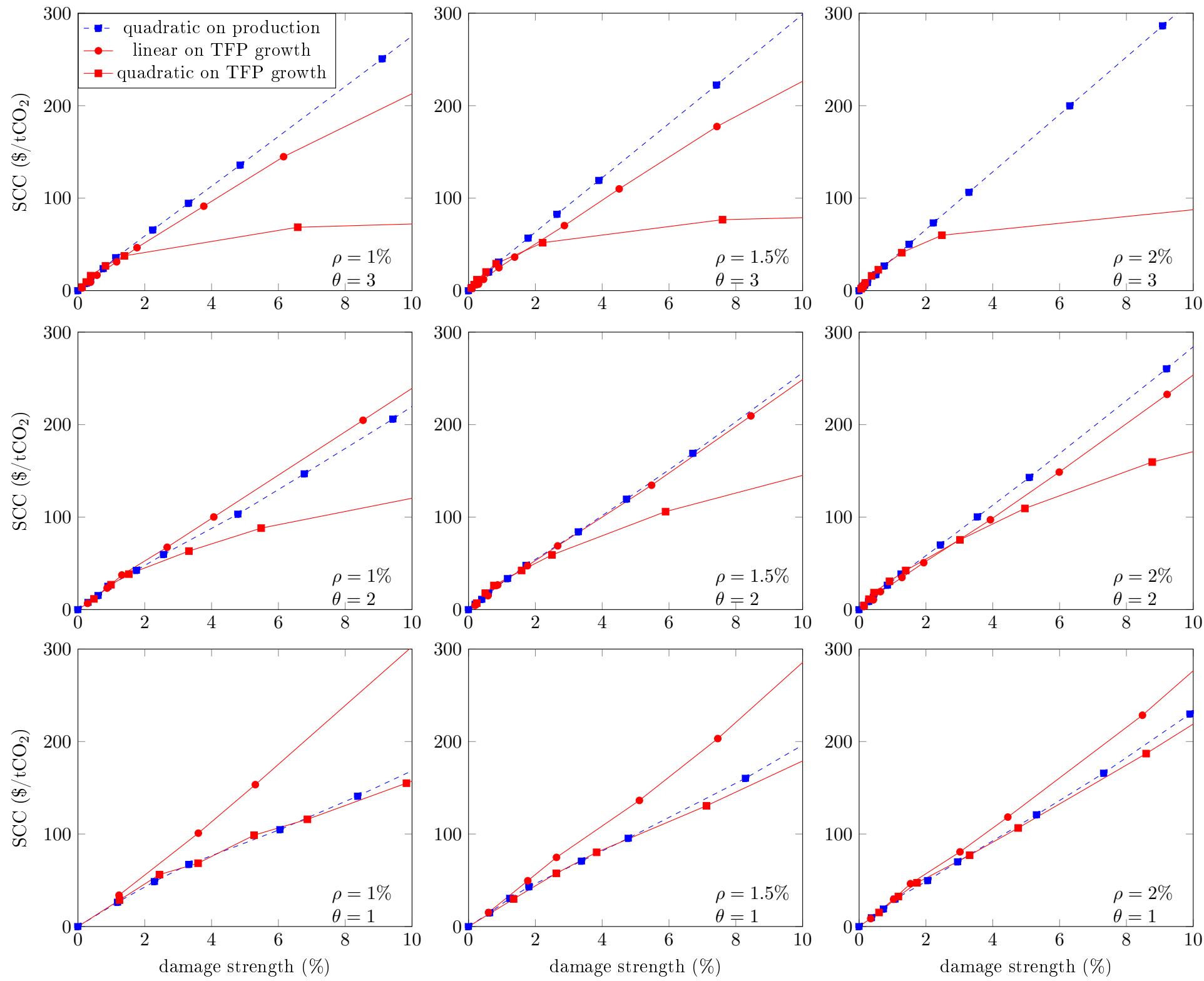

Figure 1: SCC as a function of damage strength. Increasing $\rho$ from left to right, increasing $\theta$ from bottom to top.

The main result is that there is no unequivocal ranking of the dashed line with respects to the solid lines. This is sufficient to conclude that having damage on growth does not necessarily lead to higher social cost of carbon than having damage on production, when damage strength is kept equal. This depends both on the welfare parameters and the precise functional forms for damage (linear or quadratic). This result puts into perspective previous works cited in the introduction. Their message was that SCC is higher when damage on TFP growth are taken into account. We show that this is not necessarily the case when the damage strength is controlled for. The explanation is that introducing 
damage on TFP growth increases aggregate damage (see appendix 1).

If we look more precisely at the curves, we can say that:

- when damage is quadratic, SCC is higher when damage bears on production than when they bear on growth for the range of $\rho$ and $\theta$ tested. Indeed the solid line with square marks is always below the dashed line.

Note that when $\theta=1$, there is almost no difference.

- the comparison between damage on production and linear damage on TFP growth depends on the welfare parameters. So whether having damage on growth induces higher SCC depends strongly on the social welfare function with which outcomes are evaluated. We can see that when $\theta$ is high $(=3)$, the SCC is higher when damage is on production. But when $\theta$ is low $(=1)$, the SCC is higher when damage is on growth. For intermediate $\theta(=2)$, the ranking depends on the rate of pure timepreference: the dashed line is below the solid line with circle marks when $\rho$ is low and above when $\rho$ is high. With linear damage on growth, putting more weight to long run, i.e. lowering $\rho$ or $\theta$, is sufficient to have higher SCC.

These results make an intuitive sense. Indeed, for the same damage strength, damage on TFP growth is more spread out across time than damage on production (see figure 4). To have the same intertemporal aggregate damage, damage on production at a given date must be higher in the short to medium run, whereas damage on growth is mainly concentrated in the long and very long run. Because the SCC is the discounted sum of marginal impacts, putting more weight on the long run, i.e. lowering $\rho$ or $\theta$, will tend to produce a higher SCC with damage on growth, relative to the SCC with damage on production. Indeed, at high $\theta$, the SCC with damage on production is well above the SCC with damage on growth, whereas at low $\theta$, the SCC with damage on production is below the SCC with linear damage on growth and slightly above, but very close to, the SCC with quadratic damage on growth. With linear damage on growth, damage is higher in the medium run than with quadratic damage on growth, which leads to higher SCC. The curves are also sensitive to $\rho$ but much less than to $\theta$.

To sum up, there is no straightforward relationship between the damage structure and the SCC. Having damage on growth rather than on production does not increase the SCC: the effect depends on the welfare parameters.

This situation for the SCC, with no unequivocal relationship, can be contrasted with the comparison of the welfare loss $l$ between the optimal policy and the idealine, as defined in the fourth paragraph of section 3.3. By definition, the welfare loss, that compares welfare between the optimal policy and the idealine, will be lower than the damage strength, that compares welfare between the no-mitigation policy (baseline) and the idealine ${ }^{6}$. Therefore, the relation between welfare loss and damage strength will stay below the bisectrix of the first quadrant.

The welfare loss between optimal policy and the idealine as a function of damage strength is depicted in figure 2, with the same convention as in figure 1 . Here we have a straightforward ranking between the three damage structures under scrutiny, for the range of parameters explored. For a given damage strength, the final welfare, after mitigation, will be higher with quadratic damage on growth and lower with linear damage on growth. Quadratic damage on production is a median situation. Alternatively, we can say that

${ }^{6}$ This is the same as saying that mitigation gain are always positive, see (13). 
mitigation reduces damage more when damage are quadratic than linear, and more when they bear on TFP growth than on production.

For a given damage strength, damage will not be distributed with the same temporal profile for different damage structures (see figure 4). With quadratic functional form, damage is quite low at the beginning, but increase on the medium term. Thus it is mainly concentrated in the long-run. With linear functional form, damage is substantial from the very beginning. Damage is thus more uniformly spread across time. Now, a mitigation policy has almost no effect in the short run, this means that it can mostly offset damage in the long-run. As the long-run damage takes a greater share of the overall level of damage with a quadratic functional form, welfare loss is less important in this case than with a linear functional form. Regarding the difference between quadratic damage on production and on growth, the effect is the same, as damage on growth mainly occurs in the very long term, they can be more easily offset by a mitigation policy.

As shown in figure 3, for the mitigation gain between the optimal policy and the baseline, there is also a straightforward ranking between the three damage structures under scrutiny, for the range of parameters explored. For a given damage strength, the welfare gain due to mitigation is higher with quadratic damage on growth and lower with linear damage on growth. Quadratic damage on production is a median situation, and almost coincides with the case of quadratic damage on growth when $\theta=1$. The intuition for this result is the same as for welfare loss: mitigation action can better offset damage that occur in the long term.

\section{Conclusion}

In this article, we compared, in a simple climate-economy model, the effect of three damage structures on the value of the SCC. We found that the ranking of SCC between a model with damage on production and a model with damage on TFP growth is not unequivocal. It depends on welfare parameters such as the utility discount rate or the elasticity of marginal social utility of consumption. Quadratic damage on growth does give a lower SCC than quadratic damage on production, for the range of welfare parameters we considered; however, the comparison of quadratic damage on production and linear damage on growth depends on the welfare parameters. When the pure time-preference rate and the elasticity of marginal utility are low, the SCC is higher with damage on growth. On the contrary, when pure time-preference rate and the elasticity of marginal utility are high, damage on production gives a higher SCC. Based on recent econometric studies, several authors asserted that climate damage is higher than previous evaluations (see Tol $(2009,2014)$ for a review of these previous evaluations), and imply higher SCC because they affect TFP and not only production. We do not challenge this point. However, it can be inferred from our results that the higher SCC values come in fact from two effects: one linked to higher aggregate damage than previously evaluated, the other linked to the location of damage on TFP.

To compare damage structures, we have followed Stern (2006) and defined a measure of aggregate damage based on welfare variation, that we called damage strength. It allows disentangling the role of the magnitude of damage (the damage strength) from the role of the representation of damage, what we have called a damage structure. The first one is the magnitude of climate damage: damage can be low or high. The second one is the location of damage: on production, on TFP growth, as analyzed in this article, but also maybe on capital, or on working hours, on population, etc. These are two different questions because a high magnitude of damage can be represented within a damage structure on 

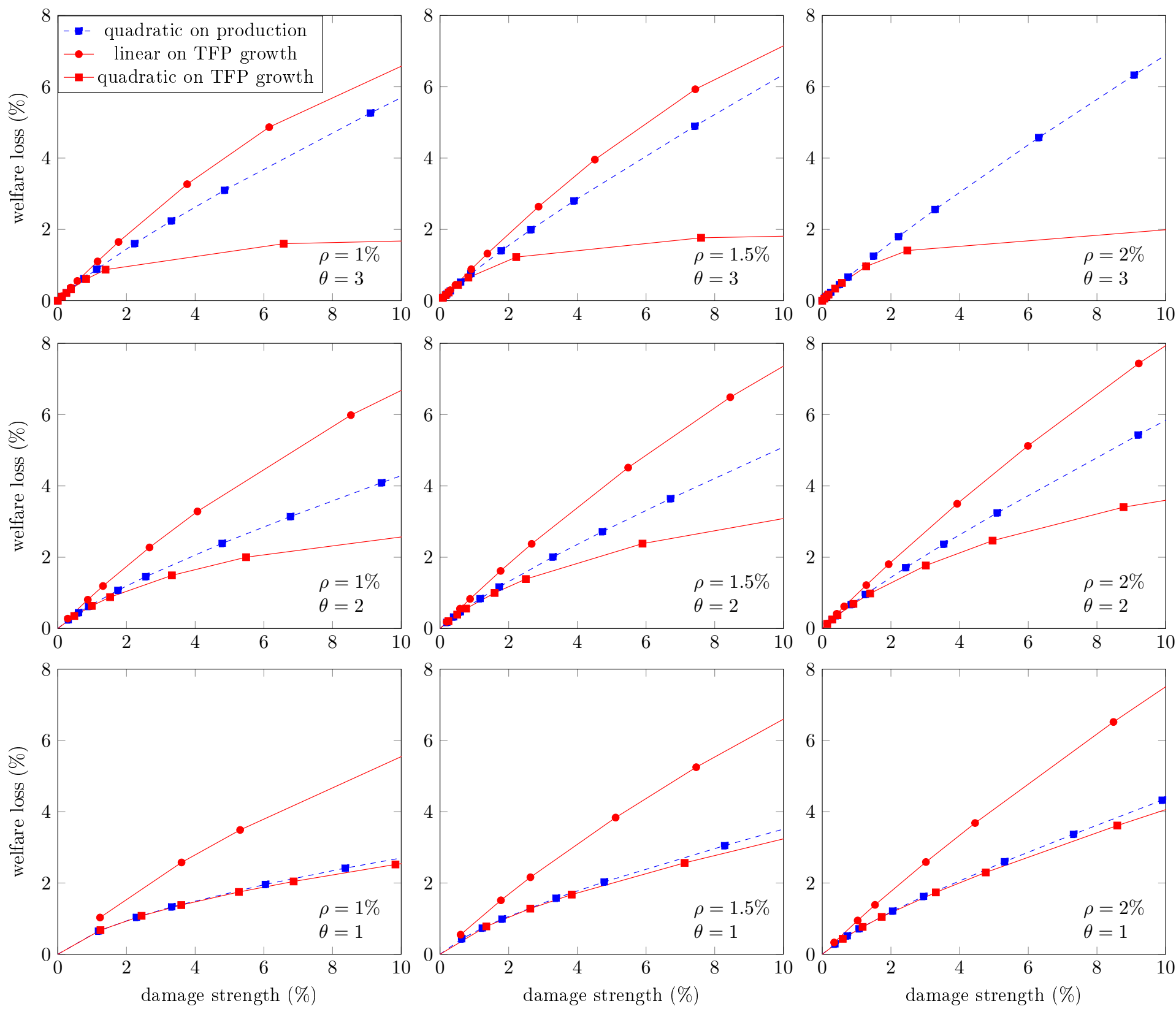

Figure 2: Welfare loss $l$ between the optimal policy and the idealine, as a function of damage strength. Increasing $\rho$ from left to right, increasing $\theta$ from bottom to top.

production only, whereas a low magnitude of damage can just as well be represented within a damage structure on TFP growth. Measuring aggregate damage at only one reference point (for example $2.5^{\circ} \mathrm{C}$ ) as Kopp et al. (2012) or only in a given timeframe as Pottier et al. (2015), is not appropriate because it does not account for the whole trajectory of damage, especially when different damage structures are involved. The damage strength we use has the advantage of accounting for this whole trajectory.

However, the measure of damage strength has one main limitation: it is not observable and the link with empirical data is thus not direct. One would hope that empirical studies would be able to identify simultaneously the magnitude of damage and its structure. In the term of our model, empirical studies would then be able to give values to the triplet of 

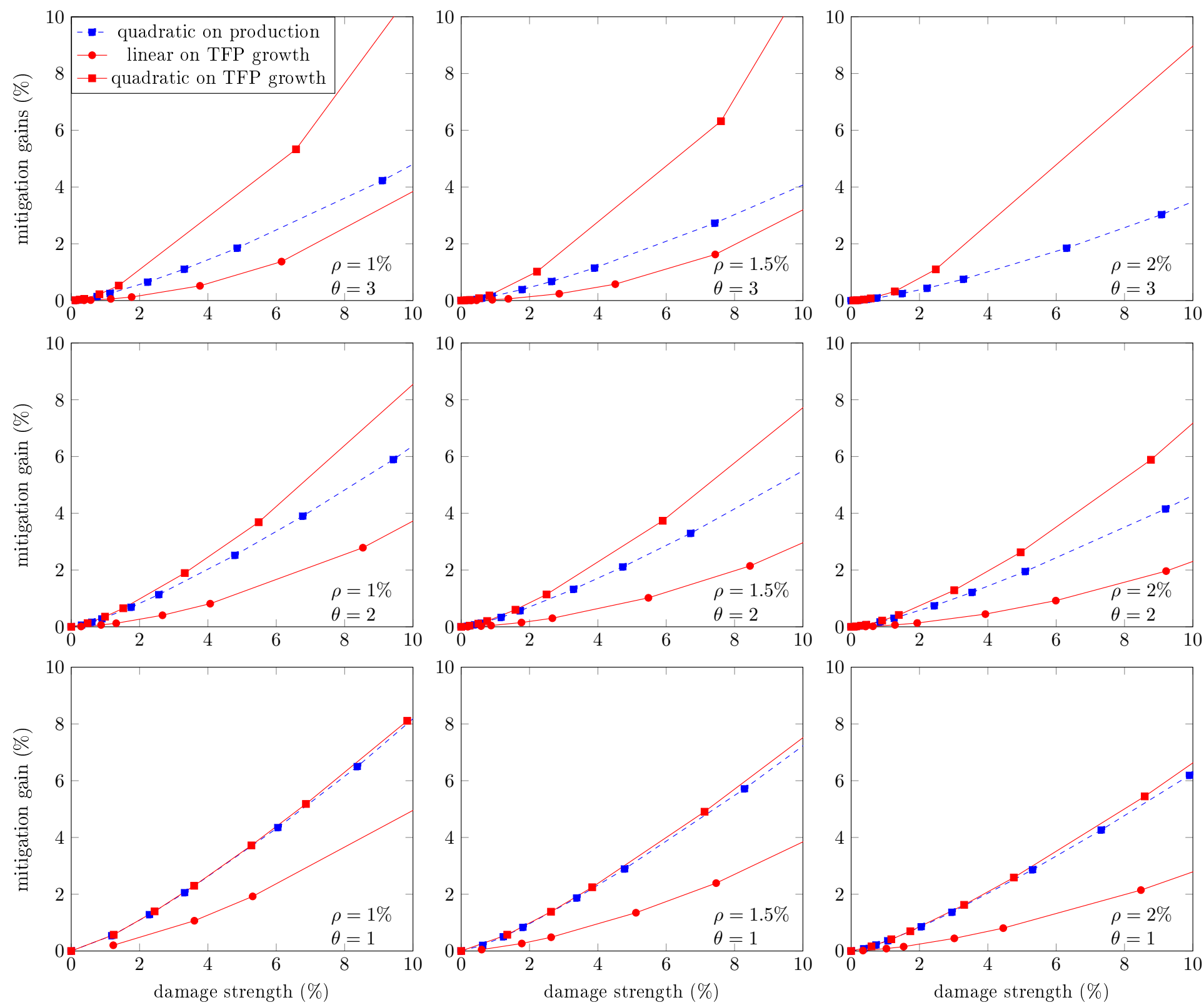

Figure 3: Mitigation gain $g$ between the optimal policy and the baseline, as a function of damage strength. Increasing $\rho$ from left to right, increasing $\theta$ from bottom to top.

$\pi_{2}, \kappa_{1}, \kappa_{2}$ (and potentially values for parameters representing damage located on channels not represented in our model but that are likely to exist in reality, e.g. damage on capital, on working hours, on population, etc.) that represents the "true" nature of climate damage in the real world. However the relationship between the representation of damage in an IAM and empirical data is more complex.

First, the identification of econometric effects is not an easy task, depends on many assumptions and remains debated. Indeed, econometric studies rely on economic output (GDP) and economic growth (ratio of GDP between two years). What is observed is a time series of economic (GDP) growth rates. From this point of observation, all damages structures considered in this article boil down to a reduction of yearly growth rate. Inferring the damage structure from observations of economic growth data is thus not a straightforward 


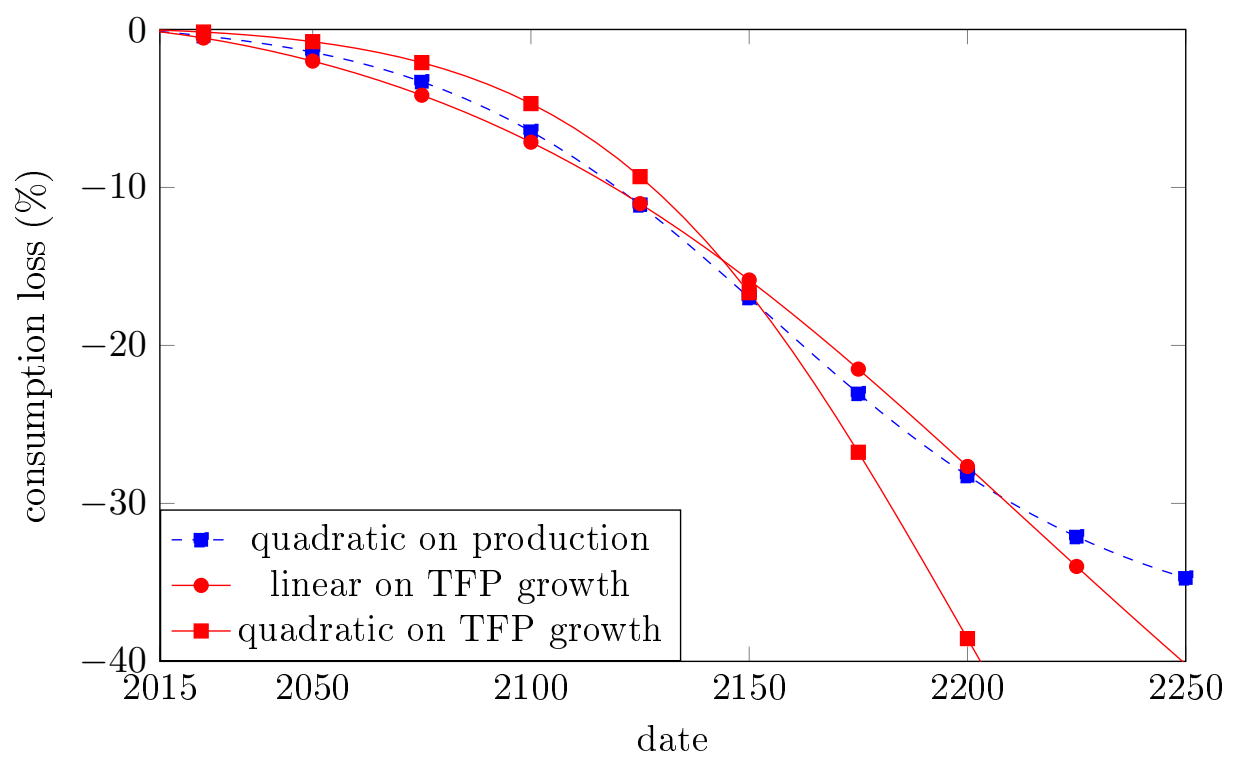

Figure 4: Consumption loss between baseline and idealine for three damage structures. Damage strength is $3 \%, \rho=1.5 \%$ and $\theta=2$.

task, and relies necessarily on disputable choices and assumptions, especially regarding the functional forms chosen and the identification strategies. Econometric studies used variations of annual temperature across space or, more preferably, across time. An instantaneous effect of a shock of annual temperature is denominated a "production impact" of climate change and a persistent effect is denominated a (GDP) "growth impact" of climate change. Strictly speaking, it does not identify parameters of the climate damage structure, but parameters of the response to weather changes. Whether the response of societies to changing weather conditions is a good proxy for their response to climate change is still controversial (see for example the differing positions expressed in Auffhammer et al. (2013), Dell et al. (2014) and Hsiang (2016), see also Schneider (1997) for an early discussion of this debate). Therefore, the empirical identification of climate damage, whether on production or on GDP growth, is not yet firmly established in the econometric literature.

Second, it is currently not possible to relate directly the coefficients of econometric regression to the parameters of a damage structure in an IAM. Indeed, there is potentially not a unique set of parameters of the IAM to reproduce empirical observation, due to the plausible co-existence of a number of channels of damage (on output, on growth, on capital, on working hours, on population...) that are not all estimated jointly in econometric studies. Therefore, parameters are under-determined. Furthermore, the representation of feedbacks in an IAM structure (e.g. through saving rates, or with TFP increasing endogenously with the capital stock) changes the ultimate effect of damage on actual GDP growth, such that parameters of damage functions have to be changed from the econometric coefficients to reproduce observations. Moore and Diaz (2015) is a first attempt to calibrate parameters of damage functions in an IAM on econometric results (from Dell et al. (2012)), which illustrates the fact that parameters are not directly equal to econometric coefficients.

Despite valuable insights provided by empirical studies of economic impacts, we are still a long way from a comprehensive identification of the damage parameters to be used in the IAMs. To realistically calibrate the representation of damage in IAMs, further methodological and empirical investigations are critical. In the mean time, different choices for the representation of damage in an IAM will co-exist. This is the reason why we need 
to address the kind of question asked in this paper: what is the impact on the SCC of different damage structures, given a magnitude of damage. When discussing climate damage, authors should distinguish between the impact on the SCC and the impact on the damage strength, between the impact on the marginal damage and the impact on aggregate damage. To do so, a good practice would be to systematically report the SCC along with the damage strength or another measure of the magnitude of damage. If the damage strength cannot be used to directly make the link between models and empirical observation, it can be reported in modelling studies to disentangle how much of the results is due to the magnitude of damage, and how much is due to the very nature of the alternative representation tested.

\section{Appendix 1}

Moyer et al. (2014) and Dietz and Stern (2015) rely on the same representation of the impact of climate change on productivity growth. They start from damage bearing only on production, with a damage function $D_{t}$ that depends quadratically on the temperature $T_{t}: D_{t}=1-\Omega\left(T_{t}\right)$. Net production (that is including climate damage) $Q_{t}$ is reduced by a factor $1-D_{t}$ from $Y_{t}$, the production that would have occured given factors on production (technology, capital, labor), had climate change not existed: $Q_{t}=Y_{t}\left(1-D_{t}\right)$

From this standard case, the current damage $D_{t}$ are then "allocated" between damage on production and damage on TFP growth, a procedure that originates, to our knowledge, from Kopp et al. (2012). The TFP growth rate is reduced by $f . D_{t}$, when the production, instead of being reduced by $1-D_{t}$ is reduced by $\left(1-D_{t}\right) /\left(1-f D_{t}\right)$, where $f$ is the "share" of damage that impact growth. Speaking of an "allocation" of damage conveys the impression that there is the same "amount" of damage.

However the damage apply on very different quantities. Damage on TFP growth have a (first-order) cumulative effect on the whole output path, whereas damage on production does not ${ }^{7}$. Far from keeping aggregate damage constant across the scenarios studied, the allocation introduces more damage when $f$ increases. Thus, it is not surprising that these studies find that the SCC increases when more damage are allocated to damage on growth. To illustrate this, we consider two possible ways to measure aggregate damage: the real production loss and the damage strength used in the main text.

Figure 5 plots the real production loss at $3^{\circ} \mathrm{C}$ (the percentage of production loss between the baseline and the idealine when the temperature increase reaches $3{ }^{\circ} \mathrm{C}$ ) against the theoretical loss (the value of $D_{t}$ when the temperature increase is $3^{\circ} \mathrm{C}$ ), for several "shares" of damage on growth: $0,2.5,5,10,15$ and 20 (percents). Because temperature increase feedbacks on the economic dynamic and thus on emissions, the date at which $3^{\circ} \mathrm{C}$ is reached changes slightly when the theoretical loss and the "share" vary.

When damage bear only on production, real losses are already higher than the theoretical damage from the damage function (equal theoretical and real damage is represented by the dotted line in figure 5). This is due to feedbacks through reduced accumulation of capital. But the difference between real and theoretical losses remains quite small. When the "share" of damage on TFP growth increases, the wedge between the real loss and the theoretical loss increases rapidly. This is of course no surprise, because the damage that reduces long-term growth rates has long-lasting effects. However it has the consequence that damage is much higher at $3^{\circ} \mathrm{C}$ than what is commonly assumed. This means that the value of reduction of output at $3^{\circ} \mathrm{C}$ is not kept constant.

\footnotetext{
${ }^{7}$ As explained in the main text, damage on production have a second-order cumulative effect through reduced capital accumulation.
} 


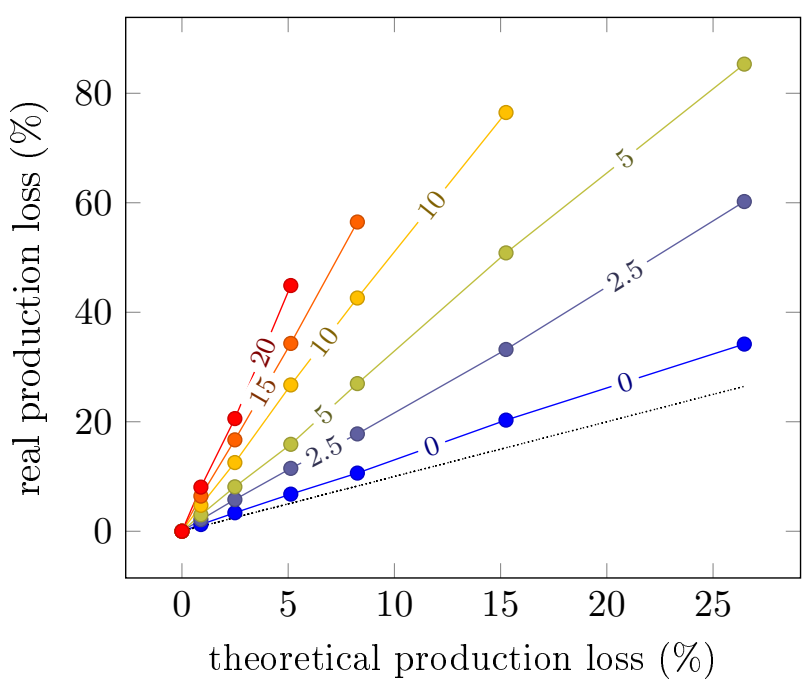

Figure 5: Real production losses as a function of theoretical production losses, for different "shares" of damage on growth $f$ increasing from 0 to 20 percents.

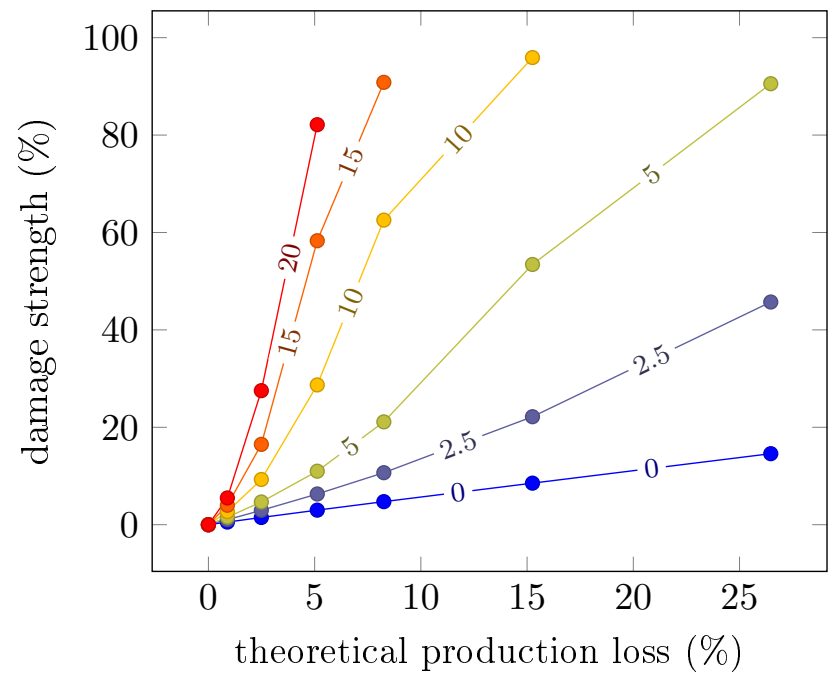

Figure 6: Damage strength as a function of theoretical production losses, for different "shares" of damage on growth $f$ increasing from 0 to 20 percents.

Figure 6 plots the damage strength against the theoretical production loss. We can see that theoretical loss and damage strength goes in the same direction. Therefore, when the "share" of damage on TFP growth is kept constant, theoretical loss can be used as a proxy for damage strength. However, when the "share" of damage on TFP growth is changed, the same theoretical loss can lead to highly different damage strengths.

\section{Appendix 2 (online)}

The model is resolved over a 600 years time horizon, by 5 years time steps. It is calibrated in 2005. Table 2 gives the parameters values.

In addition, four variables follow exogenous trends, as defined below:

$g_{t}=g_{0} e^{-\chi t}$ (exogenous trend of TFP growth) 


\begin{tabular}{|l|l|l|l|}
\hline parameters & values & units & names \\
\hline$A_{0}$ & 0.02722 & - & Initial level of TFP \\
\hline$L_{0}$ & 6514 & million & Initial world population \\
\hline$K_{0}$ & 137 & trillion $\$$ & Initial value of world capital \\
\hline$\alpha$ & 0.3 & - & Capital elasticity in production function \\
\hline$\delta$ & $10 \%$ & - & Depreciation rate of capital per year \\
\hline$\theta_{2}$ & 2.8 & - & Exponent of abatement cost function \\
\hline$\beta$ & 2 & $\mathrm{~K} / \mathrm{TtC}$ & $\begin{array}{l}\text { Parameter linking cumulative emissions and } \\
\text { temperature increase }\end{array}$ \\
\hline
\end{tabular}

Table 2: Values of model parameters.

$L_{t}=L_{0} e^{-\gamma t}+L_{\infty}\left(1-e^{-\gamma t}\right)$ (population)

$\sigma_{t}=\sigma_{0} e^{-g_{\sigma} t e^{-d_{\sigma} t}} \frac{1+e^{-s_{\text {peak }} d_{\text {peak }}}}{1+e^{s_{\text {peak }}\left(t-d_{\text {peak }}\right)}}$ (exogenous evolution in carbon content of production)

$\theta_{1}(t)=\sigma_{t} \frac{p_{\text {backstop }}}{\theta_{2}} \frac{r_{\text {backstop }}-1+e^{-g_{\text {backstop }} t}}{r_{\text {backstop }}}$ (exogenous decrease of abatement costs)

Table 3 gives the values of the parameters used in these four exogenous trends.

\begin{tabular}{|l|l|l|l|}
\hline parameters & values & units & names \\
\hline$g_{0}$ & $0.92 \%$ & - & Initial growth rate of TFP per year \\
\hline$\chi$ & $0.1 \%$ & - & $\begin{array}{l}\text { Rate of decline of exogenous trend of TFP } \\
\text { growth per year }\end{array}$ \\
\hline$\gamma$ & $3.5 \%$ & - & Initial growth rate of population per year \\
\hline$L_{\infty}$ & 8600 & million & Asymptotic population \\
\hline$\sigma_{0}$ & 0.00013418 & tC $\$$ & Initial carbon content of production \\
\hline$g_{\sigma}$ & $0.73 \%$ & - & $\begin{array}{l}\text { Initial decrease rate of carbon content of pro- } \\
\text { duction per year }\end{array}$ \\
\hline$d_{\sigma}$ & $0.3 \%$ & - & Rate of decline of decarbonization per year \\
\hline$s_{\text {peak }}$ & 0.03 & per year & Speed of fast decline of carbon content \\
\hline$d_{\text {peak }}$ & 150 & year & Date of fast decline of carbon content \\
\hline$p_{\text {backstop }}$ & 1170 & $\$ /$ tC & Cost of backstop \\
\hline$r_{\text {backstop }}$ & 2 & - & Ratio initial to final backstop cost \\
\hline$g_{\text {backstop }}$ & $0.5 \%$ & - & Initial decline in cost of backstop per year \\
\hline
\end{tabular}

Table 3: Values of parameters defining exogenous trends.

\section{References}

Anthoff, David and Richard SJ Tol (2013) — The uncertainty about the social cost of carbon: A decomposition analysis using fund, Climatic Change 117(3), pp. 515-530.

Anthoff, David and Richard S. J. Tol (2009, July) - The Impact of Climate Change on the Balanced Growth Equivalent: An Application of FUND, Environmental and Resource Economics 43(3), pp. 351-367.

Arrow, Kenneth J. (2007, January) - Global Climate Change: A Challenge to Policy, The Economists' Voice 4 (3). 
Auffhammer, M., S. M. Hsiang, W. Schlenker, and A. Sobel (2013, July) - Using Weather Data and Climate Model Output in Economic Analyses of Climate Change, Review of Environmental Economics and Policy 7(2), pp. 181-198.

Colacito, Riccardo, Bridget Hoffmann, and Toan Phan (2014, December) - Temperatures and Growth: A Panel Analysis of the U.S., SSRN Scholarly Paper ID 2546456, Social Science Research Network, Rochester, NY.

Committee on Assessing Approaches to Updating the Social Cost of Carbon, Board on Environmental Change and Society, Division of Behavioral and Social Sciences and Education, and National Academies of Sciences, Engineering, And Medicine (2017) - Valuing Climate Changes: Updating Estimation of the Social Cost of Carbon Dioxide, Washington, D.C.: National Academies Press, DOI: $10.17226 / 24651$.

Dasgupta, Partha (2007) — The Stern Review's economics of climate change, National institute economic review, pp. 4-7.

Dell, Melissa, Benjamin F. Jones, and Benjamin A. Olken (2009) - Temperature and Income: Reconciling New Cross-Sectional and Panel Estimates, American Economic Review 99(2), pp. 198-204.

Dell, Melissa, Benjamin F. Jones, and Benjamin A. Olken (2012, July) - Temperature Shocks and Economic Growth: Evidence from the Last Half Century, American Economic Journal: Macroeconomics 4(3), pp. 66-95.

Dell, Melissa, Benjamin F. Jones, and Benjamin A. Olken (2014) - What Do We Learn from the Weather? The New Climate-Economy Literature, Journal of Economic Literature 52(3), pp. 740-798.

Deryugina, Tatyana and Solomon M. Hsiang (2014, December) - Does the Environment Still Matter? Daily Temperature and Income in the United States, Working Paper 20750, National Bureau of Economic Research.

Dietz, Simon and Nicholas Stern (2015, March) - Endogenous Growth, Convexity of Damage and Climate Risk: How Nordhaus' Framework Supports Deep Cuts in Carbon Emissions, The Economic Journal 125(583), pp. 574-620.

Fankhauser, Samuel and Richard S.J. Tol (2005, January) - On climate change and economic growth, Resource and Energy Economics 27(1), pp. 1-17.

Gillett, Nathan P., Vivek K. Arora, Damon Matthews, and Myles R. Allen (2013, March) - Constraining the Ratio of Global Warming to Cumulative CO2 Emissions Using CMIP5 Simulations*, Journal of Climate 26(18), pp. 6844-6858.

GODARD, Olivier (2009) - Time discounting and long-run issues: the controversy raised by the Stern Review of the economics of climate change, OPEC energy review 33(1), pp. 1-22.

Goodwin, Philip, Richard G. Williams, and Andy Ridgwell (2015, January) - Sensitivity of climate to cumulative carbon emissions due to compensation of ocean heat and carbon uptake, Nature Geoscience 8(1), pp. 29-34. 
Greenstone, Michael, Elizabeth Kopits, and Ann Wolverton (2013, January) Developing a Social Cost of Carbon for US Regulatory Analysis: A Methodology and Interpretation, Review of Environmental Economics and Policy 7(1), pp. 23-46.

Hope, Chris (2013) - Critical issues for the calculation of the social cost of CO2: why the estimates from PAGE09 are higher than those from PAGE2002, Climatic Change 117(3), pp. 531-543.

Hsiang, Solomon (2016, October) - Climate Econometrics, Annual Review of Resource Economics 8(1), pp. 43-75.

Hsiang, Solomon M. and Amir S. Jina (2014, July) — The Causal Effect of Environmental Catastrophe on Long-Run Economic Growth: Evidence From 6,700 Cyclones, Working Paper 20352, National Bureau of Economic Research.

Interagency Working Group on Social Cost of Carbon (2010) - Social Cost of Carbon for Regulatory Impact Analysis under Executive Order 12866., Technical report, United States Government.

Interagency Working Group on Social Cost of Carbon (2015) - Technical Update of the Social Cost of Carbon for Regulatory Impact Analysis Under Executive Order 12866., Technical report, United States Government.

Kopp, Robert, Richard Tol, and Stephanie Waldhoff (Eds.) (2012) - The Social Cost of Carbon, http://www.economics-ejournal.org/special-areas/special-issues/the-socialcost-of-carbon. Special Issue of Economics: The Open-Access, Open-Assessment EJournal.

Kopp, Robert E., Alexander Golub, Nathaniel O. Keohane, and Chikara Onda (2012) - The Influence of the Specification of Climate Change Damages on the Social Cost of Carbon, Economics: The Open-Access, Open-Assessment E-Journal.

Krasting, J. P., J. P. Dunne, E. Shevliakova, and R. J. Stouffer (2014, April) Trajectory sensitivity of the transient climate response to cumulative carbon emissions, Geophysical Research Letters 41(7), pp. 2520-2527.

Leduc, Martin, H. Damon Matthews, and Ramón De Elía (2015, December) - Quantifying the Limits of a Linear Temperature Response to Cumulative $\mathrm{CO}_{2}$ Emissions, Journal of Climate 28(24), pp. 9955-9968.

LuCAS, JR, Robert E. (1987) - Models of business cycles, Oxford, Royaume-Uni: Basic Blackwell.

Lucas, JR, Robert E. (2003, March) - Macroeconomic Priorities, The American Economic Review 93(1), pp. 1-14.

Matthews, H. Damon, Nathan P. Gillett, Peter A. Stott, and Kirsten Zickfeld (2009) - The proportionality of global warming to cumulative carbon emissions, $\mathrm{Na}$ ture 459 (7248), pp. 829-832.

Mirrlees, James A. and Nicholas H. Stern (1972, April) - Fairly good plans, Journal of Economic Theory 4(2), pp. 268-288. 
Moore, Frances C. and Delavane B. Diaz (2015, February) - Temperature impacts on economic growth warrant stringent mitigation policy, Nature Climate Change 5(2), pp. $127-131$.

Moyer, Elisabeth J., Mark D. Woolley, Nathan J. Matteson, Michael J. Glotter, and David A. Weisbach (2014, June) - Climate Impacts on Economic Growth as Drivers of Uncertainty in the Social Cost of Carbon, The Journal of Legal Studies 43(2), pp. 401-425.

Nordhaus, W. D. (1992) - An optimal transition path for controlling greenhouse gases, Science 258(5086), pp. 1315-1319.

Nordhaus, William D. (1994) - Managing the Global Commons: The Economics of Climate Change, Cambridge (Mass.): MIT Press.

Nordhaus, William D. (2008) - A Question of Balance, London: Yale University Press.

Nordhaus, William D. (2010) - Economic aspects of global warming in a postCopenhagen environment, Proceedings of the National Academy of Sciences 107(26), pp. 11721-11726.

PinDyCK, Robert S. (2011) - Modeling the Impact of Warming in Climate Change Economics, in G. LibecaP And R. Steckel (Eds.), The Economics of Climate Change. Chicago: University of Chicago Press.

PINDYCK, Robert S. (2012, May) - Uncertain outcomes and climate change policy, Journal of Environmental Economics and Management 63(3), pp. 289-303.

Pizer, William, Matthew Adler, Joseph Aldy, David Anthoff, Maureen CropPer, Kenneth Gillingham, Michael Greenstone, Brian Murray, Richard Newell, Richard Richels, Arden Rowell, Stephanie Waldhoff, and Jonathan Wiener (2014, May) - Using and improving the social cost of carbon, Science $\mathbf{3 4 \boldsymbol { 6 }}(6214)$, pp. 1189-1190.

Pottier, Antonin, Etienne Espagne, Baptiste Perrissin-Fabert, and Patrice Dumas (2015) — The comparative impact of Integrated Assessment Models' structures on optimal mitigation policies, Environmental Modelling $\&$ Assessment 20(5), pp. 453473.

Revesz, Richard L., Peter H. Howard, Kenneth Arrow, Lawrence H. Goulder, Robert E. Kopp, Michael A. Livermore, Michael Oppenheimer, and Thomas Sterner (2014) - Global warming: Improve economic models of climate change, Nature 508(7495), pp. 173.

Riahi, Keywan, Detlef P. van Vuuren, Elmar Kriegler, Jae Edmonds, Brian C. O'Neill, Shinichiro Fujimori, Nico Bauer, Katherine Calvin, Rob Dellink, Oliver Fricko, Wolfgang Lutz, Alexander Popp, Jesus Crespo Cuaresma, Samir KC, Marian Leimbach, Leiwen Jiang, Tom Kram, Shilpa RaO, Johannes Emmerling, Kristie Ebi, Tomoko Hasegawa, Petr Havlik, Florian Humpenöder, Lara Aleluia Da Silva, Steve Smith, Elke Stehfest, Valentina Bosetti, Jiyong Eom, David GernaAt, Toshihiko Masui, Joeri Rogelu, Jessica Strefler, Laurent Drouet, Volker Krey, Gunnar Luderer, Mathijs Harmsen, Kiyoshi Takahashi, Lavinia Baumstark, Jonathan C. Doelman, Mikiko Kainuma, Zbigniew Klimont, Giacomo Marangoni, Hermann 
Lotze-Campen, Michael Obersteiner, Andrzej Tabeau, and Massimo Tavoni (2017) - The Shared Socioeconomic Pathways and their energy, land use, and greenhouse gas emissions implications: An overview, Global Environmental Change.

SchneIDER, Stephen H. (1997, December) - Integrated assessment modeling of global climate change: Transparent rational tool for policy making or opaque screen hiding value-laden assumptions?, Environmental Modeling 63 Assessment 2(4), pp. 229-249.

Stern, Nicholas (1977) - Welfare weights and the elasticity of the marginal valuation of income, in M. Artis and A. Nobay (eds), Studies in Modern economic Analysis, Oxford: Blackwell.

Stern, Nicholas (2014a) - Ethics, equity and the economics of climate change paper 1: Science and philosophy, Economics and Philosophy 30(03), pp. 397-444.

Stern, Nicholas (2014b) - Ethics, equity and the economics of climate change paper 2: Economics and politics, Economics and Philosophy 30(03), pp. 445-501.

Stern, Nicholas H. (2006) - Stern Review: The Economics of Climate Change, Volume 30, London: HM treasury.

Strulik, Holger (2015, January) - Hyperbolic discounting and endogenous growth, Economics Letters 126, pp. 131-134.

ToL, Richard SJ (2009) — The economic effects of climate change, The Journal of Economic Perspectives, pp. 29-51.

ToL, Richard SJ (2014) — Correction and Update: The Economic Effects of Climate Change, The Journal of Economic Perspectives 28(2), pp. 221-225. 